\title{
Políticas públicas, migración y familia. Una mirada desde el género
}

\author{
Claudia Pedone \\ Institut d'Infancia i Món Urbà (CIIMU). Barcelona (España) \\ claudiapedone@yahoo.es \\ Belén Agrela Romero \\ Universidad de Jaén \\ bagrela@ujaen.es

\section{Sandra Gil Araujo} \\ Universidad de Buenos Aires. Facultad de Ciencias Sociales. \\ Instituto de Investigaciones Gino Germani. \\ sandragilaraujo@yahoo.es
}

\section{Resumen}

El objetivo de este texto es explorar y visibilizar las vinculaciones de las políticas y los discursos sobre migración familiar, con los proyectos y las trayectorias de las familias migrantes y sus variadas formas de inclusión o exclusión. Considerando el proceso de feminización de la migración latinoamericana hacia España, nuestra atención se centra en las imbricaciones entre las políticas y los discursos públicos y las formas de organización de las familias migrantes. Un acercamiento que conlleva una contribución al campo de los estudios migratorios, en tanto implica una articulación entre la dimensión conceptual, la dimensión política y normativa y la dimensión micro y subjetiva de la migración.

Los resultados presentados derivan del análisis desde una perspectiva de género de normativas y documentos públicos; entrevistas en profundidad con representantes de los principales partidos públicos a nivel estatal y autonómico y un trabajo de campo etnográfico con mujeres bolivianas y dominicanas asentadas en Cataluña. En concreto, nuestro estudio está orientado a explorar los aspectos siguientes: 1 . De qué manera las políticas de migración familiar asignan diferentes derechos a la población migrante, en relación con el género, la edad, el estatus legal, la nacionalidad y el tiempo de llegada. 2. Cuáles son las consecuencias empíricas que las políticas tienen en las modalidades de reagrupación familiar y en las relaciones familiares según el género, la edad, las trayectorias migratorias, el origen nacional y la inserción en el mercado de trabajo. 3. Cómo los migrantes, sus hijos, sus hijas y sus familias responden y desafían una regulación de la migración familiar cada vez más restrictiva.

Palabras clave: inmigrantes latinoamericanos; reagrupamiento familiar; estratificación cívica; migración familiar; política migratoria; España. 
Abstract. Public policies, migration and family: A gender approach

The main purpose of this article is to explore and make visible the links between family immigration policies and discourses with the migration projects and trajectories of migrant families and their various forms of inclusion/exclusion. Taking into account the process of feminisation of Latin American migrations to Spain, we focus on the interweaving of public policies and discourses and the way in which migrants organise their family life. This approach contributes to the field of migration studies as it combines the conceptual dimension, the political and normative dimension and the subjective and micro dimension of migration processes.

The results are obtained through a gender-based analysis of public documents and regulations, interviews with representatives of the main national and regional political parties, and ethnographic field work with Bolivian and Dominican women who have settled in Catalonia. Our study aims to explore (i) how family migration policies assign different rights to migrants depending on their gender, generation, legal status, nationality and time of arrival; (ii) the empirical consequences of policies on family reunification schemes and family relations according to gender, age, different stages of the migration project, national origins, times of arrival, and access to the labour market; and (iii) how migrants and their sons, daughters and families respond to and challenge increasingly restrictive family migration regulations.

Keywords: Latin American immigrants; family reunification; civic stratification; family migration strategies; migration policy; Spain.

\begin{tabular}{|c|c|}
\hline \multicolumn{2}{|c|}{ Sumario } \\
\hline 1. Introducción & 4. Políticas migratorias y estrategias \\
\hline $\begin{array}{l}\text { 2. Antecedentes y consideraciones } \\
\text { teóricas sobre la migración familiar }\end{array}$ & $\begin{array}{l}\text { de las familias migrantes latinoamericanas } \\
\text { 5. Notas finales }\end{array}$ \\
\hline $\begin{array}{l}\text { 3. La regulación de la migración } \\
\text { familiar en España }\end{array}$ & Referencias bibliográficas \\
\hline
\end{tabular}

\section{Introducción}

En Europa, los recientes estudios sobre migración familiar se han centrado principalmente en la unidad familiar en los países receptores, pero son muy incipientes las investigaciones que indagan la incidencia que tienen las políticas migratorias en las formas de organización de la vida familiar ${ }^{1}$. Siguiendo a Kofman (2004), la marginalización teórica y empírica de la migración familiar responde a la preponderancia de la perspectiva economicista en los estudios migratorios, la concepción de la migración como una transacción entre indi-

1. Algunos ejemplos de las primeras indagaciones en este terreno pueden encontrarse en el libro editado por Kofman et al. (2011), que incluye una investigación de Riaño sobre el impacto de las políticas de migración familiar en las relaciones de género y en la integración social de las mujeres migrantes latinoamericanas en Suiza. 
viduos y estados y la asociación de la migración femenina con la dicotomía de varones productores y mujeres reproductoras. Fueron los análisis sobre redes migratorias desde la perspectiva transnacional — atentos a las relaciones de género- los que hicieron emerger las dinámicas familiares como terrenos de investigación y producción de conocimiento sobre los movimientos migratorios (Mahler y Pessar, 2006).

Paralelamente, la desigualdad de género de las políticas de migración familiar ha recibido, hasta ahora, una atención insuficiente (Bhabha y Sutter, 1994; Carling, 2005). Las críticas feministas del modelo del varón como sostén de la familia han evidenciado que las mujeres también estaban migrando como trabajadoras y de forma independiente. Sin embargo, se ha desatendido el hecho de que, cada vez más, son los varones quienes utilizan modos de entrada relacionados con la familia. Los efectos que tiene el uso de estos canales sobre las identidades sociales, de género y generacionales de las personas migrantes, su estatus socioeconómico y sus vías de inserción, así como sobre las relaciones de género y generacionales dentro de la familia, no han sido hasta ahora objeto de un análisis pormenorizado. En definitiva, se conoce muy poco el impacto que las políticas de migración familiar tienen sobre varones y mujeres y las generaciones más jóvenes reagrupadas.

En el contexto español, los flujos migratorios que en los últimos quince años han experimentado un proceso más claro de aceleración ${ }^{2}$ y feminización $^{3}$ provienen de América Latina, particularmente de Ecuador, Colombia, República Dominicana y, más recientemente, de Bolivia, Brasil y Paraguay. Este doble proceso ha tenido un impacto transformador en las estructuras familiares, donde se produce una reacomodación de las relaciones de género y

2. Con el término aceleración se hace referencia al rápido y abrupto crecimiento del número de inmigrantes latinoamericanos a inicios del siglo XXI. Este proceso implicó el inicio de una nueva fase migratoria que transformó a América Latina en la principal región de origen de la inmigración en España y convirtió a España en el segundo país de destino de la migración latinoamericana, después de EE UU. Los inmigrantes de América Latina documentados pasaron de 61.000 en 1991 a 514.485 a finales de 2003, y representaban el 31,2\% de la inmigración regularizada. En el año 2003, la comunidad latinoamericana estaba representada por 1.310.000 habitantes, los inmigrantes ecuatorianos en primer lugar, con 497.799, les seguían, por lugar de origen, Colombia (271.239), Argentina (152.975), Bolivia (97.947), Perú (85.029), República Dominicana (57.134) y Brasil (54.115). Entre los años 2000 y 2005, la inmigración latinoamericana en España creció un 663\% (Gil Araujo, 2008b). En marzo de 2010, el 29,99\% de la población extranjera en España era latinoamericana y continuaba encabezando la lista Ecuador, con 437.279 personas. La migración latinoamericana continúa teniendo rostro femenino: en cinco de las quince principales nacionalidades se contabilizan más mujeres que hombres; Bolivia (58,73\%), República Dominicana $(58,29 \%)$, Colombia (55,94\%), Perú (51,04\%) y Ecuador (50,73\%) (OPI, 2010).

3. Con el término feminización de las migraciones latinoamericanas queremos resaltar el papel de gran parte de las mujeres migrantes de América Latina como: a) primer eslabón de la cadena migratoria hacia España, $b$ ) pioneras del proyecto migratorio familiar y $c$ ) iniciadoras y responsables de los procesos de reunificación familiar. No pretendemos entrar en un debate sobre si las mujeres son o no mayoría en estos flujos, sino enfatizar los cambios que la migración liderada por mujeres genera en las relaciones de género y generacionales dentro de las familias. 
generacionales y un cambio en las modalidades de reagrupación familiar y en las experiencias de los hijos y las hijas de familias migrantes, tanto en los lugares de origen como de destino. Paralelamente, la migración familiar, hasta ahora ignorada en el discurso político y en las estadísticas, ha devenido un tema de debate público y emerge bajo problematizaciones que ubican a la familia como territorio de intervención preferencial en términos de gestión de la integración.

En los países europeos receptores de inmigración, las familias migrantes se han convertido en objeto de control de las políticas migratorias y, paralelamente, las políticas de migración familiar se han ido transformando en instrumento de restricción y selección de inmigrantes (Gil Araujo, 2010). En línea con la limitación al derecho de migración familiar en los países europeos, la última modificación de la Ley de Extranjería española en 2009 impone nuevas limitaciones al derecho de reagrupación familiar. Sin embargo, tanto las políticas como los procesos empíricos reales de la migración familiar son, hasta el momento, un campo de investigación relativamente poco explorado.

El principal objetivo de este artículo es analizar cómo las actuales políticas de migración familiar, además de profundizar los procesos de estratificación cívica, inciden en los modos de organización familiar y en la consolidación de los procesos de transnacionalismo. Es importante aclarar que, si bien en esta oportunidad nos centramos en las políticas migratorias, en ningún caso consideramos que son el único condicionante de las formas que adquieren los procesos de reunificación familiar. Partimos de investigaciones previas (Gil y Agrela, 2008; Agrela, 2006; Gil Araujo, 2009; Pedone, 2006a; Agrela et al., 2008), en cuyo marco hemos constatado cómo, en el contexto español, las regulaciones formales e informales de las migraciones no comunitarias fomentan la proliferación de diferentes niveles de estratificación civica y socioeconómica, en relación con el género, la edad y la nacionalidad, especialmente en el caso de las migraciones por motivos familiares.

Los hallazgos que se presentan en este artículo provienen de trabajos de campo realizados en varios proyectos de investigación llevados a cabo por las autoras. En 2006 y 2007, realizamos un estudio exploratorio sobre la regulación de la migración familiar y el impacto estratificador de derechos de estas políticas en el contexto español. Entrevistamos a dieciséis personas: una abogada especializada en extranjería de una ONG pro inmigrantes, una mediadora social, dos representantes de asociaciones de inmigrantes y nueve mujeres y tres varones inmigrantes de distintas nacionalidades y estatutos administrativos. Todas estas personas estaban involucradas en procesos de reagrupación familiar formales o autónomos (Gil Araujo, 2009) . En el año 2007, se efectuaron quince entrevistas en profundidad a mujeres y varones migrantes bolivianos en Cataluña, poniendo énfasis en la historia migrato-

4. En el marco del proyecto Civic Stratification, Gender and Family Migration Policies in Europe, financiado por el NODE Research Programme, del Ministerio Federal de Ciencia e Investigación de Austria. 
ria, la mujer como primer eslabón de la cadena migratoria y reagrupante, inserción laboral, nuevas formas de organización familiar y estatus jurídico (Pedone, 2007). Entre el 2008 y el 2011, dentro de un estudio sobre el uso del espacio público teniendo en cuenta el género, la generación, la procedencia y el estatus jurídico, se llevaron a cabo veinticinco entrevistas a varones y mujeres migrantes, centrando los ejes de las entrevistas en la historia familiar, la situación legal y laboral, el uso del espacio público y las prácticas transnacionales (Pedone, Gil Araujo, Agrela Romero y Solavagione, 2010)5. A partir de 2010 y hasta la actualidad, se realiza trabajo de campo transnacional principalmente con familias migrantes latinoamericanas, utilizando técnicas cualitativas de carácter etnográfico y biográfico: $a$ ) entrevistas en profundidad a miembros de familias migrantes (en origen y en destino), expertos y expertas, abogados y abogadas, personal de la Administración pública, técnicos y técnicas de inmigración y miembros de varias ONG y asociaciones migrantes, tanto en el ámbito estatal, como autonómico y municipal, y b) recopilación y análisis de fuentes secundarias, documentos (legislaciones, planes, informes) $\mathrm{y}$ declaraciones de representantes institucionales en los medios de referencia ${ }^{6}$. Por último, las entrevistas con representantes de partidos políticos fueron desarrolladas durante el año 2009. Los apartados de preguntas apuntaban a revelar sus opiniones sobre distintos aspectos de las políticas migratorias, el acceso a la nacionalidad y la ciudadanía de las personas migrantes ${ }^{7}$.

A lo largo de este texto mostraremos, en primer lugar, cómo las regulaciones jurídicas y el estatus administrativo condicionan las vías que se siguen para la migración familiar y evidencian el impacto que los cambios legislativos tienen en las formas de organizar la migración. A continuación presentamos un breve repaso de los estudios realizados en el campo de la migración familiar, para luego resumir las formas de pensar la migración familiar en las políticas públicas y en el debate político español. Posteriormente, identificamos algunas de las estrategias desplegadas por las familias migrantes latinoamericanas, basándonos en entrevistas con mujeres procedentes de Bolivia y República Dominicana. La elección de estos dos grupos nacionales se basa en el papel de las mujeres como pioneras de estos desplazamientos, los distintos momentos de llegada y la diversidad de estatutos jurídicos. El artículo se cierra con algunas conclusiones sobre las vinculaciones entre las políticas migratorias, los procesos de estratificación cívica y las formas de

5. En el marco del proyecto europeo Gender, Migration and Intercultural Interactions in the Mediterranean and South East Europe: an interdisciplinary perspective (GE.M.IC), programa Marco 7, financiado por la Unión Europea.

6. En el marco del proyecto en curso Politicas migratorias, transnacionalismo familiar y estratificación civica: Las migraciones latinoamericanas hacia España. MICIIN, I+D+I (CSO20091349, subprograma SOCI). Equipo investigador: Claudia Pedone (IP), Sandra Gil Araujo, María Margarita Echeverri y Belén Agrela Romero

7. Entrevistas realizadas por Sandra Gil Araujo en el marco del proyecto EUROSPHERE Diversity and the European Public Sphere. Towards a Citizens' Europe, financiado por la Comisión Europea, programa Marco 6 (2007-2012).. 
organización de las familias migrantes latinoamericanas en España en un contexto de crisis global.

\section{Antecedentes y consideraciones teóricas sobre la migración familiar}

La investigación sobre los efectos que tiene la migración en las relaciones de género y generacionales en las familias migrantes es incipiente en Europa en general, pero muy particularmente en España (Gregorio, 2002; Oso, 2007; Pedone, 2006a, 2007, 2008; Solé y Parella, 2005; Suárez y Crespo, 2004), donde es llamativa la falta de datos estadísticos sobre migración por motivos familiares y la escasez de investigaciones sobre políticas de migración familiar que vayan más allá de un análisis de la normativa de reunificación.

La migración internacional provoca un reajuste en el interior de la familia, en las relaciones entre mujeres y hombres y entre las generaciones. Se observa, en primer lugar, una negociación de las relaciones familiares. En segundo lugar, se identifican variaciones en las modalidades de reagrupación familiar, organizada por el miembro de la familia que ha emigrado. Y, en tercer lugar, se reconocen diferencias entre las vivencias de los hijos e hijas de familias migrantes, tanto en el lugar de origen como en el de destino (Aparicio, 2007; Gregorio, 1998, 2002; Herrera, 2004; Lagomarsino, 2004; Levitt y Walter, 2002; Pedone, 2004a, 2004b, 2005a, 2005b, 2006a, 2006b, 2006c, 2010).

Aunque, en la última década, numerosas investigaciones cualitativas han puesto de relieve la diversidad, la heterogeneidad y la complejidad de los proyectos, las dinámicas, las prácticas y las estrategias migratorias de las familias latinoamericanas ${ }^{8}$, las retóricas políticas, mediáticas y educativas tienden a presentar imágenes en exceso homogéneas e indiferenciadas de estos flujos migratorios que dificultan la inserción de los migrantes y las migrantes (Agrela, 2009; Agrela y Gil, 2005; Pedone, 2006a). Los estudios señalados han demostrado que estos desplazamientos se generan a partir de decisiones que involucran a la mayor parte de los miembros de grupos domésticos extensos y que, por ello, la familia se revela como un espacio de negociación pero también de conflicto.

Por otro lado, el aumento y la diversidad de las poblaciones migrantes —en relación con el género, la edad, los orígenes socioeconómicos y nacionales, las destrezas, los niveles educativos, los proyectos migratorios-, unidos a la complejidad de las legislaciones que regulan sus ingresos, sus residencias, sus empleos y sus accesos a la nacionalidad, han impulsado el debate acerca del

8. Para la inmigración latinoamericana: Herranz, 1998; Camarero y García-Borrego, 2004; Riaño, 2007; para la República Dominicana: Gregorio, 1998, 2002; Sorensen, 2004, 2005a, 2005b; para el Perú: Tornos et. al., 1997 y Escrivá, 1997, 2000; para Colombia: Carrasquilla Coral y Echeverri Buriticá, 2003; Echeverri Buriticá, 2005, 2010; Aparicio y Giménez, 2003; INSTRAW-OIM, 2007; para el caso del Ecuador: Pedone, 2004a y 2004b; para el caso de mujeres ecuatorianas y colombianas: Oso, 2002; para hogares transnacionales peruanos y ecuatorianos: Parella y Cavalcanti, 2007; para familias transnacionales bolivianas: Hinojosa Gordonava, 2009; Parella y Cavalcanti, 2010; para familias transnacionales colombianas: Medina Villegas, 2009; Rivas y Gonzálvez, 2010. 
desarrollo de sistemas de derechos diferenciados y estratificados, lo que Morris (2002, 2003) y Kofman (2002, 2004), entre otros autores, denominan Civic Stratification.

A través de mecanismos varios (procedimientos de admisión, condicionalidades, restricciones y requisitos), las leyes de extranjería asignan derechos diferentes a distintas categorías de migrantes. De este modo, las normas migratorias crean nuevas formas de desigualdad (Agrela, 2006, 2009), pero también refuerzan las inequidades económicas y sociales preexistentes y las divisiones basadas en las relaciones de género y generacionales. Un buen ejemplo del efecto estratificador de la implementación de ciertos derechos lo encontramos en las políticas de migración familiar (Gil Araujo, 2009). Que los criterios para el acceso a la reunificación familiar sean objetivos no significa que no operen de manera diferente. Incluso si se formulan en términos aparentemente neutros, los diferentes derechos atados a la ordenación de la inmigración y la residencia suelen operar de una forma marcada por el género (Freedman, 2003), la nacionalidad y la edad?

Así, las normas sobre migración entran claramente en contradicción con la concepción inclusiva de la ciudadanía cívica promovida por la Comisión Europea (Bauböck, 2004; European Commission, 2003), presente también en las políticas públicas diseñadas en el contexto español, por ejemplo: el Plan Estratégico de Ciudadanía e Integración (2007-2010, 2011-2014) de la Secretaría de Estado de Inmigración y Emigración, el Pla de Ciutadania i Immigració 2005-2008 y el Pacte Nacional per a la Immigració de la Generalitat de Catalunya.

Los estatus jurídicos asignados por las regulaciones de inmigración son claves a la hora de restringir o impulsar el alcance de la capacidad de agencia de las personas migrantes. En este sentido, la legislación migratoria puede ser vista como una parte importante de la estructura de oportunidades políticas y discursivas (Koopmans y Statham, 2000) y un factor crucial que condiciona el modo y el grado de participación de los migrantes en la sociedad en su conjunto.

Con las distintas investigaciones que dan contenido a este artículo ${ }^{10}$, buscamos avanzar en el conocimiento de las imbricaciones entre las políticas de migración familiar y las estrategias de las familias migrantes. Nuestra perspectiva supone una aportación al campo de los estudios migratorios, en tanto conlleva una articulación entre la dimensión conceptual (definición de familia), la dimensión política y normativa (regulación de migraciones familiares e intervención pública) y la dimensión subjetiva y micro de estos procesos (reorgani-

9. En este sentido, la retórica sobre los derechos de la infancia enmudece arbitrariamente cuando los sujetos de atención cumplen dieciocho años. Es decir, cuando se convierten en personas adultas cesan todos sus derechos, no sólo porque pierden los que les corresponden por dejar de ser menores (Jiménez, 2005; Agrela et al., 2008), sino que se les niegan aquellos no atribuibles por su condición de extranjeros, lo cual les sitúa en una posición de ciudadanía muy precaria o, incluso, inexistente (CIIMU, 2004).

10. Ver de nota 4 a 7 . 
zación familiar, reajustes en las relaciones de género y generacionales). Nuestro interés pasa por articular el binomio formado por argumentación teórica y contrastación empírica. Centrándonos en el ámbito conceptual y normativo, a continuación analizamos la regulación de la migración familiar en España, con especial atención a las formas de pensar los vínculos entre migración, género y familia en las políticas públicas y en los discursos políticos.

\section{La regulación de la migración familiar en España}

En el contexto español, las familias migrantes han estado ausentes de las políticas y de los discursos sobre migración. La primera Ley de Extranjería de 1985 no contemplaba el derecho de reagrupación familiar, y por eso tampoco preveía un procedimiento para la gestión de la admisión de familiares de las personas extranjeras residentes, si bien algunas disposiciones establecían ciertas particularidades para la obtención de permisos fundamentados en el vínculo familiar. No sería hasta diez años después cuando, en la Resolución de febrero de 1994, se dictaron instrucciones generales para el procedimiento sobre tramitación de visados para la reagrupación familiar de extranjeros no nacionales de los estados miembros de la UE. A partir de esa regulación, comenzaron a diferenciarse los inmigrantes no comunitarios de los familiares de españoles y de nacionales europeos. Para las reagrupaciones de familiares de inmigrantes no comunitarios, se estableció que el reagrupante tenía que acreditar recursos económicos estables y suficientes para cubrir las necesidades de su familia y una vivienda de dimensiones y características «consideradas normales» según el modelo español. En el Reglamento de 1996, quedaron excluidos expresamente de la vía de la reunificación familiar los hijos mayores de edad, los nietos y los bisnietos. El reglamento articuló por primera vez el rechazo a la poligamia, el fraude y la doble exigencia con respecto a los ascendientes de tener razones justificadas y demostrar la dependencia económica. Las personas reagrupadas continuaron teniendo limitado su acceso al mercado laboral, siguiendo la lógica de la conexión entre inmigración y trabajo que atraviesa el tratamiento de la inmigración y las reglamentaciones de la reagrupación familiar.

Hasta la Ley de 2000, la reagrupación fue regulada desde la discrecionalidad administrativa. Con la Ley de Extranjería 4/2000, por primera vez aparece un capítulo dedicado a la reagrupación familiar en el marco de los derechos y los deberes de los extranjeros, si bien la primera modificación se llevó a cabo menos de un año después de su entrada en vigor. Con la Ley Orgánica 8/2000, de 22 de diciembre, se estableció un tiempo de convivencia en España durante el cual el cónyuge no puede desvincularse del reagrupante (dos años) y se redujo la lista de reagrupables. En los procedimientos, se recuperaron las restricciones anteriores a la Ley 4/2000: permiso de residencia renovado, vivienda adecuada y medios de subsistencia suficientes. Uno de los objetivos mencionados para la reforma de la Ley en 2003 fue evitar fraudes en las reagrupaciones familiares en cadena. Desde entonces, sólo puede reagrupar un trabajador residente a título 
propio. Desaparece también la exención de visado para los familiares que ya se encuentran de forma irregular en España.

Teniendo en cuenta que los trabajos a los que acceden los migrantes latinoamericanos suelen ser de bajos salarios y no siempre se reflejan en un contrato, los requisitos de ingresos, contrato y vivienda vigentes en la actualidad se convierten muchas veces en obstáculos para la reagrupación familiar, sobre todo en el caso de las mujeres, para quienes el trabajo doméstico o de cuidados suele ser la primera vía de inserción en el mercado laboral español, tal como han mostrado diversas investigaciones ${ }^{11}$ y hemos comprobado en nuestros trabajos de campo (Agrela, 2012; Agrela, Martín y Langa, 2010). Cabe aclarar que estos requerimientos no se aplican a la población inmigrante con nacionalidad española.

Desde el comienzo de la tematización de la inmigración en términos de integración, las familias migrantes ( $\mathrm{y}$, dentro de ellas, especialmente las mujeres) devinieron objeto de intervención de las políticas públicas. En este marco, la reunificación familiar fue concebida en los discursos y en las políticas públicas como una herramienta de integración de inmigrantes. Incluso el establecimiento de requisitos económicos y una vivienda «normal» fueron justificados como un instrumento para garantizar la integración de las familias migrantes.

Si bien a lo largo de la última década muchas mujeres encabezan el proyecto migratorio familiar, las políticas las conciben como miembros reagrupados junto a sus hijos. Esta concepción sigue estando muy presente en la óptica de diversos actores y refleja el modo tan extendido de pensar a las mujeres como reproductoras biológicas y simbólicas de la nación (y su cultura), naturalmente ligadas al ámbito familiar. En palabras de un representante político de Cataluña, se refleja esta postura:

11. Los datos del último proceso de regularización de 2005 muestran la importancia del servicio doméstico como vía de regularización para las mujeres inmigrantes no comunitarias. El $41,24 \%$ de las 687.138 solicitudes de regularización fueron presentadas por mujeres, con importantes diferencias según la nacionalidad. El $31,67 \%$ fue para el empleo de hogar; el 20,76\% para la construcción; el 14,16\% para la agricultura y la ganadería y el $10,36 \%$ para la hostelería. De las solicitudes para el sector de hogar el $83,40 \%$ eran femeninas. Datos presentados por el Colectivo IOE (2010) basados en la Encuesta Nacional a Inmigrantes de 2007 indican que el servicio doméstico fue el primer trabajo en España para el 38\% de la población inmigrante femenina. Considerando los países de origen, tuvieron su primer trabajo en este sector el $74 \%$ de las mujeres bolivianas y el $50 \%$ de las procedentes de Ecuador, Perú, República Dominicana y Colombia. Según datos del Ministerio de Trabajo e Inmigración, en mayo de 2011, un 93\% de las 296.498 personas dadas de alta en el Régimen Especial de Empleo de Hogar eran mujeres, el $61 \%$ de ellas extranjeras. Pero la realidad supera con creces estas cifras: el empleo doméstico sigue siendo el nicho de la economía sumergida que permite a muchas mujeres inmigrantes insertarse en el mundo laboral con independencia de su nivel de cualificación o su situación administrativa. Muchas asociaciones de empleadas de hogar elevan la cifra de mujeres que trabajan en el sector hasta las 700.000 (Gil Araujo y González, en prensa). 
Es que para mí, sinceramente, la reagrupación familiar debe ser un elemento inmediato, se debe facilitar y creo que, en este sentido, la reforma que plantea el Gobierno de España en la Ley de Extranjería y el ministro Corbacho en este sentido me parece muy, muy acertada. Se potencia que el marido pueda reagrupar a su mujer y puedan reagrupar también con facilidad a los hijos [...] Además que no entiendo sinceramente cómo podemos pensar en una integración de alguien que vive entre nosotros sin que esté con él su familia. Pienso que la familia ayuda muchísimo en la integración, a la adaptación y a la tranquilidad, y a la estabilidad de la persona del país donde vive. (Representante del PSC)

La conexión entre género, familia e integración está presente en la filosofía de diversos planes y programas, tanto a nivel estatal como autonómico. En el primer plan estatal dirigido a la población migrante (Plan Interministerial para la Integración Social de los Inmigrantes), elaborado por el Ministerio de Asuntos Sociales en 1994, la integración se planteaba insistiendo en cuestiones culturales y en la inmigración de tipo familiar, haciendo hincapié en el papel preponderante de la mujer y su rol de puente entre la sociedad de origen y destino, en tanto reproductora y adaptadora socializadora de las unidades familiares:

La alfabetización y la adaptación de la mujer tiene importancia estratégica, no sólo por su importancia numérica, sino por su papel esencial para lograr que toda la familia se adapte al nuevo contexto social. (PISI, Dirección General de Migraciones 1995: 60)

En el segundo plan estatal, el Programa Global de Regulación y Coordinación de Extranjería e Inmigración (GRECO) (2000-2004), la tramitación de la reagrupación para los familiares de las personas extranjeras residentes en territorio español se presentó como uno de los mecanismos más importantes para conseguir la plena integración de los inmigrantes en nuestra sociedad. En los diferentes planes y programas de integración autonómicos y municipales, puestos en marcha mayoritariamente desde principios de 2000, la familia de los migrantes es reiteradamente definida como instrumento de integración (Agrela, 2006, 2009).

La naturalización del vínculo familiar y el consecuente nexo entre familia e integración emerge del mismo modo en gran parte de las entrevistas realizadas a representantes de partidos políticos en Cataluña. En algunos casos, se insiste en la necesidad de limitar a los familiares que puedan entrar en la reagrupación.

Los elementos de reunificación familiar son elementos necesariamente... Se dan de forma natural, es decir, yo creo que lo que hay que hacer es posibilitar y regular porque no necesitan promoción. El vínculo familiar está promocionado de forma natural y de forma espontánea. (Representante de EUiA)

Yo creo que hay un mínimo que se tiene que permitir, lo que pasa es que luego hay que ver donde está este mínimo y marcarlo. Es difícil esto, establecer con justicia, todos los casos [...] Como mínimo, los hijos y la pareja, pues esto es necesario, luego a partir de ahí si la hermana, el hermano, el suegro, la suegra... 
Aquí se puede hacer una cadena interminable y que sería, seguramente, insostenible. Pero hay un mínimo que se tiene que permitir. (Representante de CIU-1)

Bueno, creo que hay que mantener la reunificación familiar en el núcleo real de lo que es familiar y suficiente para dar estabilidad al inmigrante, más allá no. Hablo de un concepto de familia que si, o sea, estrictamente el concepto occidental, podemos estirarlo un poco pero no tiene porque llegar al concepto de... Nuestro concepto de familia y la justificación en términos políticos, siendo fríos, términos políticos es porque es parte de la estabilidad del propio inmigrante, por tanto, contribuye, es humana y contribuye a la estabilidad del propio inmigrante. Cónyuges e hijos seguro, y en algunos casos padres, y a lo mejor le pondría padres de cierta edad. O sea, uno puede traer a sus padres de más de 60 años y si no, no los puede traer. Por ejemplo, los padres tienen 40 y yo 20 años no tengo porque traerlos; si tiene 40 y los padres 60 pues si los puede traer, jugar un poco con eso, los ascendientes, hasta abuelos si tienen más de 70, al jugar un poco con eso se podría ser mucho más rigurosos en lo que es la reunificación familiar. (Representante de CiU-2)

Como detallamos a continuación, la limitación en el derecho de reagrupación de los ascendientes fue uno de los núcleos centrales de la última reforma de Ley Orgánica 4/2000, de 11 de enero, sobre derechos y libertades de los extranjeros en España y su integración social.

\subsection{La reagrupación familiar en la última reforma}

En el año 2008, la reunificación familiar, hasta entonces omitida en los debates y en las estadísticas sobre inmigración, irrumpió en el ámbito político a través de las declaraciones del Ministro de Trabajo e Inmigración que alertaban sobre la necesidad de establecer un mayor control de estos flujos. En ese contexto, el ex ministro Celestino Corbacho propuso recortar el derecho de reagrupación de los ascendientes (padres, madres, suegros y suegras) de la población inmigrante no comunitaria. Estas recomendaciones fueron plasmadas en la última reforma de la Ley Orgánica 4/2000, publicada en el Boletín Oficial de las Cortes Generales el 1 de julio de $2009^{12}$ y aprobada por el Congreso de los Diputados el 7 de diciembre del mismo año. Según el texto de la reforma:

[...] el cambio fundamental que se introduce es que los beneficiarios de la reagrupación, en línea con lo que ocurre en la mayoría de los países de nuestro entorno, se acotan básicamente a los familiares que integran la familia nuclear; la novedad en este caso es que dentro de esta categoría de familiares se incluye a la pareja que tenga con el reagrupante análoga relación de afectividad que el cónyuge en el matrimonio y que a estos reagrupados se les facilita el acceso inmediato al mercado de trabajo. En cambio, esta reforma lleva a que la reagrupación de los ascendentes se limite como norma general a los mayores de sesenta y cinco años, previendo que puedan existir razones humanitarias que la permitan con una edad inferior. (Proyecto de Ley Orgánica de reforma de 
la Ley Orgánica 4/2000, de 11 de enero, sobre derechos y libertades de los extranjeros en España y su integración social, 2000: 3)

En el artículo 17, se especifican las limitaciones para la reagrupación de los ascendientes: «los ascendientes del reagrupante y de su cónyuge, en línea recta y en primer grado, cuando estén a su cargo, sean mayores de sesenta y cinco años y existan razones que justifiquen la necesidad de autorizar su residencia en España» (Proyecto de Ley Orgánica de reforma de la Ley Orgánica 4/2000, de 11 de enero, sobre derechos y libertades de los extranjeros en España y su integración social, 2000: 9), pero con una salvedad, que aparece en el artículo 18 , sobre requisitos para la reagrupación familiar: estos familiares «solamente podrán ser reagrupados a partir del momento en que el solicitante adquiera la residencia de larga duración» ${ }^{13}$ (Proyecto de Ley Orgánica de reforma de la Ley Orgánica 4/2000, de 11 de enero, sobre derechos y libertades de los extranjeros en España y su integración social, 2000: 9).

Otra de las novedades del proyecto de reforma se refiere al acceso al mercado de trabajo de las personas reagrupadas. La nueva regulación de la migración familiar prevé la habilitación sin trámite alguno para trabajar a los cónyuges y descendientes en edad laboral reagrupados. Pero el texto adelanta una posible restricción: «Reglamentariamente podrá establecerse que durante el primer año de vigencia de su autorización, los familiares reagrupados sólo tengan acceso a las ocupaciones consideradas deficitarias en mano de obra según la situación nacional de empleo» (Proyecto de Ley Orgánica de reforma de la Ley Orgánica 4/2000, de 11 de enero, sobre derechos y libertades de los extranjeros en España y su integración social). Algo que, dicho en palabras de un representante de $\mathrm{CiU}$, se resume en la siguiente ecuación:

En momento de crisis, hemos de priorizar que las personas que vienen reagrupadas formen parte del contingente y que vayan vinculadas a puestos de trabajo que tengamos necesidad. (Representante de CiU-3)

Dichas restricciones no serán aplicables a los familiares de los residentes de larga duración. Esta nueva estratificación de derechos entre inmigrantes no comunitarios, según sea su estatus administrativo, es el resultado del traspaso de la directiva europea de residentes de larga duración a la legislación española ${ }^{14}$.

13. «La residencia de larga duración es la situación que autoriza a residir y trabajar en España indefinidamente en igualdad de condiciones que los españoles. Tendrán derecho a residencia de larga duración los que hayan tenido residencia temporal en España durante cinco años de forma continuada, que reúnan las condiciones que se establezcan reglamentariamente. Se considerará que la residencia ha sido continuada aunque por períodos de vacaciones u otras razones que se establezcan reglamentariamente el extranjero haya abandonado el territorio nacional temporalmente.»

14. Directiva 2003/109/CE del Consejo, de 25 de noviembre de 2003, relativa al estatuto de los nacionales de terceros países residentes de larga duración http://eur-ex.europa.eu/smartapi/ cgi/sga_doc?smartapi!celexplus!prod!DocNumber\&lg=es\&type_doc=Directive\&an_ doc $=2003 \&$ nu_doc $=109$. 
Tanto en este caso como en el proyecto de creación de un estatuto especial para los migrantes altamente cualificados (la blue card) ${ }^{15}$, la reagrupación familiar se revela como instrumento primordial de jerarquización de derechos en relación con la posibilidad de vivir en familia entre las (cada vez más) diversas categorías de inmigrantes.

En el siguiente punto, analizamos la dimensión subjetiva de los procesos de migración familiar, atendiendo a las estrategias desplegadas por las familias migrantes latinoamericanas ante los obstáculos impuestos por las regulaciones migratorias del Estado español.

\section{Políticas migratorias y estrategias de las familias migrantes latinoamericanas}

En este apartado, tomamos como caso de estudio la migración procedente de la República Dominicana y Bolivia, desplazamientos encabezados, en gran parte, por mujeres que llegaron al territorio español en diferentes épocas: a mediados de los años ochenta y mediados de la primera década del siglo XXI, respectivamente. En ambas nacionalidades, la entrada en vigor del visado ha sido un elemento clave para los cambios en las modalidades de reagrupación familiar y en la consolidación de los procesos de transnacionalismo familiar.

En los últimos quince años, las corrientes migratorias procedentes de América Latina son las que presentan signos más evidentes de aceleración y feminización, principalmente las provenientes de la República Dominicana ${ }^{16}$, y en los últimos años de Ecuador, Colombia, Bolivia, Brasil y Paraguay, sobre todo en el periodo de iniciación del flujo. Esta feminización ha generado cambios

15. La Directiva sobre las condiciones de entrada y residencia de trabajadores altamente cualificados, de octubre de 2007, pretende facilitar la contratación de trabajadores extranjeros altamente cualificados para cubrir las demandas del mercado laboral de los estados miembros, mediante la creación de la tarjeta azul, un régimen especial para este tipo de trabajadores. Para que un extranjero pueda acceder a la tarjeta azul deberá tener un contrato de por lo menos un año y recibir un salario que triplique el salario mínimo de su país de asentamiento. Una vez admitido, su conyugue recibirá automáticamente un permiso de trabajo, un derecho que, hasta el momento, no reconocen las legislaciones sobre reagrupación familiar de los trabajadores inmigrantes. Después de los dos primeros años de contratación, tendrá derecho a trabajar en cualquiera de los países comunitarios. La residencia permanente se obtendrá automáticamente a partir de los cinco años de trabajo y residencia (Gil Araujo, 2008a).

16. Uno de los primeros flujos migratorios procedentes de América Latina con rasgos acentuados de feminización fue el dominicano a mediados de la década de 1980. Coincidía con una demanda específica de mano de obra en el servicio doméstico español y una estructura familiar dominicana matrilineal. Ambos factores se conjugan para dar forma a proyectos migratorios eminentemente femeninos, con una extensa red de cuidados transnacionales que ya tenía sus antecedentes en la migración femenina hacia Estados Unidos. En este contexto migratorio, las mujeres dominicanas comienzan sus trayectorias en España hasta 1992, cuando entra en vigor el visado y las modalidades de reagrupación quedan sujetas a estas restricciones jurídicas (Pedone y Gil Araujo, 2008). 
estructurales en las relaciones de género y generacionales mantenidas hasta el momento dentro de las familias migrantes. Algunas de estas transformaciones hacen referencia a las rupturas ideológicas en torno a la concepción y el ejercicio de la maternidad (y la paternidad) (Pedone, 2004a; Solé y Parella, 2005; Medina Villegas, 2009); la creación de nuevas lealtades entre familiares (abuelas-nietos, tías-sobrinos asumen la maternidad en origen) (Pedone, 2008); varones que permanecen en origen aguardando la reagrupación por parte de las mujeres migrantes, y los cambios en las pautas de crianza y la reorganización del cuidado en un contexto transnacional (Pedone, 2010).

El papel de las mujeres como primer eslabón de la cadena migratoria ha operado como disparador de discursos sociales, políticos, educativos y mediáticos estigmatizantes que vinculan la migración femenina con el abandono de hijos e hijas. Estas visiones han instalado la idea de que la salida de la mujer supone la «desintegración familiar», lo cual invisibiliza las estrategias femeninas que ponen en marcha estos grupos domésticos para mantener los vínculos familiares y asegurar la red de cuidados en un contexto migratorio transnacional.

¿Y cómo fue la experiencia de tener la nena acá y mandarla para allá con Manuel? Fue bastante duro también.

\section{¿Cómo tomaste esa decisión?}

Pues, mi familia estaba aquí pero cada uno trabajaba. Ya sabes cómo es aquí. Mi padre trabajaba, mi madre también, y yo me veía incapaz de trabajar, de pagar una guardería... Veía que todo lo que trabajaba me iba a quedar aquí, en eso sólo, para mantenerme y mantenerla a ella.

\section{¿Y por qué Manuel no se vino cuando tuviste la nena?}

Porque tenía trabajo allí y de momento estaba allí. Entonces tuve la niña y eso... Tenía que echar pa'lante... Y entonces su hermana me dijo «mándamela» y así...

\section{¿Y no pensaste en volverte con la nena?}

No, porque él empezó un trabajo nuevo... y yo no me veía allí. Llevarla allí yo pensé que era un tiempo. Si yo me iba ya era para quedarnos. Yo pensé: la mandas para allí un tiempo y luego te la traes.

¿Y la separación cómo fue?

Me costó mucho.

¿Cuánto tiempo fue la separación de la nena?

Un año.

[...]

¿Se hizo cargo él de la crianza?

Sí, con mi hermana. Ella la cuidaba durante el día y Manuel llegaba a eso de las 6 y se hacía cargo de la niña. Una niña de cuatro meses. Y yo aquí trabajando y llamando por teléfono... 


\section{¿Y cómo gestionabas desde aqui todo el tema de la separación?}

Llamaba por teléfono todo el rato: «¿Dónde está? ¿Y ahora quién la tiene?». Y ahora esto y ahora lo otro, así. Pero bueno, ese tiempo también lo aproveché, compramos la casita. La casita era de mis padres y yo se la compré. El tiempo que no estuve con la niña lo aproveché y pude ahorrar ese dinero. Porque no tenía que mandarles dinero; él ya se ocupaba de todo. Entonces pudimos comprar la casita y entonces ya no teníamos que vivir de alquilados. Teníamos dónde estar. Entonces al final se vino.

¿Con la nena?

Sí.

(Norys, Santiago, República Dominicana, reside en Barcelona)

Las diversas estrategias de reagrupación desplegadas por las familias latinoamericanas han estado, y están, sujetas a múltiples condicionantes: el momento de llegada, la entrada en vigor del visado, la normativa de reagrupación familiar y sus requisitos económicos, las concepciones de familias implícitas en las políticas migratorias, el o la iniciadora del proyecto migratorio, la inserción laboral de los y las migrantes, los arreglos familiares y la edad de los candidatos a la reunificación (hijos o abuelos), entre otros. Pero todas estas variables están, de una u otra manera, atravesadas por la regulación migratoria. La situación administrativa irregular y/o la falta de recursos para poder cumplir con los requisitos de la reunificación formal (ingresos, contratos, vivienda) han obligado a prolongar y a profundizar las relaciones familiares transnacionales u organizar la reunificación a través de vías autónomas, ingresando "como turistas» en los casos en que no se exigía visado para estancias menores a tres meses.

Yo vine en plan de turismo, y entré por Francia, entré bien, sin problema [...] Yo entré el 9 de febrero del 2006, más o menos un año, estuve trabajando, costó, costó bastante, pero con paciencia, de a poquito, con ayuda de muy buenas personas [...] Ellas [sus hijas] han venido como turistas, igual que yo. Mi otra hermana que está hace tres años ya, tiene permiso de trabajo, les hizo la carta de invitación, a nombre de mi hermana. (Isabel, Cochabamba, Bolivia, reside en Barcelona)

Nuestro trabajo de campo muestra indicios de la influencia que tienen los cambios de las normativas en las formas de gestionar la migración familiar. Los que aparecen más reiteradamente en los relatos de nuestras entrevistadas son las modificaciones en los procedimientos para la reagrupación familiar que exigen que la persona a reagrupar esté en el país de origen y la imposición de visados para ingresar en España o en el espacio Schengen ${ }^{17}$. Ambos cambios normativos han prolongado los periodos de separación entre progenitores e

17. República Dominicana en el año 1992, Colombia en 2002, Ecuador en 2003 y Bolivia en 2007. 
hijos y han extendido el ejercicio de la maternidad y la paternidad transnacional (Pedone y Gil Araujo, 2008).

Las mujeres dominicanas y bolivianas que llegaron antes de la imposición del visado pudieron gestionar los procesos de reagrupación familiar sin grandes restricciones jurídicas, por ello, la reunificación no se limitó a varones e hijos, sino que, en algunos casos, contempló la llegada de ascendientes para organizar la red de cuidados en los lugares de destino.

Mira todo era muy diferente que ahora. Cuando llegamos éramos todas mujeres, vivíamos en pisos que alquilábamos entre todas. Todas trabajábamos en el servicio doméstico interno, y los fines de semana íbamos para el piso que compartíamos entre todas, y éramos una familia. No había hombres, en el piso no había espacio. Ahí dormíamos cuatro en una cama, sólo teníamos un colchón. Yo vine porque tenía aquí a una sobrina, en ese tiempo uno no venía con contrato, sino que entraba como turista, ellas me mandaron el dinero y compré el billete, venía con un billete de turista para tres meses pero nada, después de tres meses aquí me quedaba. El visado entró en el 92, justamente yo llegué en julio del 91, entonces fue cuando estábamos en el proceso de regularización y yo pude regularizarme ahí. A partir del 94, ya las cosas fueron cambiando porque ya fueron trayéndose a las familias, entonces estos pisos de mujeres solas se iban desarmando porque había que buscar vivienda para la familia. Se traía a los hombres primero... y, a ver..., déjame pensar... Si te hablo de mi caso y de las relaciones más cercanas, te puedo dar fe que, a partir de 1995, vienen llegando los chicos tanto pequeños como adolescentes. Hace unos tres años empezaron a llegar las abuelas, pero ellas no se quieren quedar, mi madre ha venido aquí pero se vuelve, para ellos es mucho cambio de vida, allá el abuelo siempre tiene alguien al lado, aquí vienen y están solos, es muy diferente y sufren la soledad. (Rosa, Los Ríos, República Dominicana, reside en Barcelona)

Hace 8 años que llegué a Barcelona y siempre he vivido aquí en Poble Sec. Y me gusta mucho, y ahora más porque ya están mis hijas aquí también. Es que primero vino mi hijo y más tarde mi hija, la menor. Luego, me trajeron a mí y más tarde vino mi otra hija, Miriam, con mi yerno y mi nieta. Entonces, al menos estoy con mis dos hijas, porque tuve 7 en total, aunque el más pequeño, el último se murió, entonces tengo 4 hombres y 2 mujeres, y las dos están aquí conmigo. (Nélida, Oruro, Bolivia, reside en Barcelona)

La imposición del visado a la República Dominicana en 1992 y a Bolivia en 2007 cerró las reagrupaciones por vías informales y, en muchos casos, prolongó los tiempos de separación ente cónyuges, como también entre madres, padres e hijos debido a las dificultades para cumplir con los requisitos legales, pero también por la dilatación de la Administración pública para resolver las solicitudes de reagrupación.

En cambio ahora [después de los visados] toda la generación posterior de madres y padres hacen el proceso de presentar su segunda tarjeta, presentan sus papeles a la Delegación de Gobierno de su Comunidad, y les piden un 
piso en condiciones... Un contrato de trabajo, un contrato de alquiler, y luego una persona como de asuntos sociales que van a ver el piso, luego también interviene... ya a nivel de autoridades a ver el piso en qué condiciones está, y cuando dan el visto bueno, se presenta el informe, y hay que esperar a que te envíen una carta para que se presenten allá... Yo he vivido con mucha gente que estaban haciendo el proceso, y ya cuando le dan acá el aviso de que está aprobado tienen que presentarse allá. Pero claro eso [...] la gente que lo ha hecho estamos hablando a partir de un año, a partir de un año es que está saliendo. (Mediadora)

Hasta el año 2004 aún era posible presentar un contrato de trabajo a través del sistema del Régimen General, por lo cual muchos y muchas migrantes lograban regularizarse por esta vía estando en España y así accedían a la posibilidad de reagrupar a otros miembros de la familia. Este acceso a la regularización se cierra en el año 2004 y a partir de entonces la única puerta de ingreso regular al mercado de trabajo son los contingentes que tienen que tramitarse en el país de origen. Este cambio legislativo no sólo dificulta la regularización de los migrantes y las migrantes, sino que también constituye un obstáculo para regularizar a los familiares que ingresaron por vías autónomas.

Aquí en España no tengo papeles y eso es lo que a mí ahora me tiene un poco..., porque ahora mismo ya están estudiando... Y ahora yo estoy contenta porque están conmigo. Yo las veo que están durmiendo, que han comido, yo veo, y ya estoy tranquila de que el rigor del padre ya no les hace daño. Él está allá y ya no llega nada. Pero también me da un poco de pena tener que dejarlas solas, mientras yo trabajo. Necesito trabajar para que tengan sus gastos cubiertos, me da un poquito de pena de no tener más tiempo que compartir con ellas. Y no estar aquí de una manera estable, de una manera legal, digamos. Porque yo estoy ilegal, ellas están ilegal. ¿Qué seguridad les puedo brindar? Ni siquiera de trabajo, porque no tengo de donde agarrarme. Ahora mismo no tengo de donde agarrarme, pero tampoco quiero ser pesimista. Con un permiso de trabajo y residencia tengo más chance a buscar algo mejor, más opciones, ahora no, ahora es lo que hay. A esperar. Y si fuese posible de no viajar a Bolivia, y presentar todo lo que hay que presentar aquí en España y no hacer ese viaje. (Isabel, Cochabamba, Bolivia, reside en Barcelona)

En ciertos casos, las condiciones de vulnerabilidad encontradas en los lugares de destino hacen que algunas madres valoren positivamente la construcción de vínculos familiares transnacionales, aprovechando la mayor solidez de las redes sociales en origen, debido a que la organización del cuidado es muy difícil de reconstruir en los contextos de inmigración.

Ahora mi hija vive con mi madre, quien la cuida. No es difícil que mi madre la cuide más o menos como yo quiero porque mi madre es una mujer fácil de llevar. Solo una vez tuvimos problema, al principio, porque ella gastó el dinero que yo le envié para mi hija en resolver asuntos que ella tenía que resolver. $\mathrm{Mi}$ hija me contó que su abuela no le había comprado lo que ella me había dicho 
que necesitaba, así que le pregunté a mi madre, me dijo que tenía que resolver no sé que, así que los próximos dos meses le mandé el dinero a mi hermana, le pedí que le comprara a la niña tal y tal cosa y que no le diera a la mami ni un centavo. Después hablé con mi madre y le pregunté: «Usted está segura que va a comprarle a la niña lo que yo le pida que le compre con el dinero que le mando?». Y es que yo no puedo mantenerla, para eso está su marido. Yo puedo mandarle el dinero para la niña y para su comida, bueno, pero no puedo mantenerlos a todos tampoco. Así que me dijo que así lo haría y desde entonces todo bien. Siempre le pregunto a mi niña y no hay problema. (Mariana, Santo Domingo, República Dominicana, reside en Barcelona)

Dada la antigüedad de las migraciones de República Dominicana y la preferencia otorgada por la Ley de Nacionalidad a la población inmigrante de origen latinoamericano, muchas de las mujeres dominicanas que llegaron durante las décadas de 1980 y 1990 tienen doble nacionalidad: dominicana y española (Gil Araujo, 2008b). En general, el acceso a la nacionalidad española favorece la migración circular, facilita la vida en familia y permite asumir responsabilidades y aprovechar las «ventajas» del contexto de emigración y de inmigración.

¿Y allá, quiénes hay de la familia?

Mi madre tiene a su madre. Mi padre tiene a su padre. Su madre murió el año pasado estando él allí y eso también fue bueno, porque, mira...

¿Y cómo fue esa decisión de tu padre que tiene a todos los hijos y a los nietos aquí, decir nos vamos? ¿Qué fue lo que pesó más en la decisión de tu papá y de tu mamá?

No sé. Es que aquí todo el mundo hace su mundo también... Querían irse y seguro que se lo pensarían mucho... Si están mejor allí. Aquí todo el mundo trabaja. Yo tengo a las niñas y tengo que estar pendiente de ellas, tengo que trabajar... Si aquí cada uno hace su vida, la verdad...

¿Tu mamá no hacía de abuela, eso de cuidar a todos los nietos juntos?

Ahora mismo vive allí. Pero va y viene...

¿Y cuando está aquí, les ayuda a cuidar a los chicos?

Cuando puede, porque también tiene que trabajar. Viene y se pone a trabajar.

Cuando viene, ¿ella trabaja?

Sí.

¿Y de qué trabaja?

En el servicio doméstico.

¿Sigue manteniendo los contactos para poder trabajar?

Sí.

¿En qué temporada viene? ¿Cuánto tiempo se queda cuando viene?

Esta vez lleva aquí como un año y pico... 
Es muy común entre las familias dominicanas esta migración circular, ¿no? Entre la gente de Santiago esto es muy común: venir acá por temporadas, después irse para allá para organizar a los más viejos... Tu mamá como que ha repetido ese circuito...

Es común que la gente se vaya para allá a cuidar a los viejos porque allí se hacen mayores y no tienen nada. No hay jubilación, no hay seguro médico. Allí te haces mayor y dependes de los hijos. Te has pasado la vida trabajando y al final te tiene que cuidar tu hijo, si es que puede. (Norys, Santiago, República Dominicana, reside en Barcelona)

Sin embargo, en algunos casos, la nacionalización no evita que la precariedad laboral y residencial de madres y padres en los lugares de destino vaya extendiendo los tiempos de separación previstos. Como cuenta Altagracia, que migró sola desde República Dominicana en 1998 dejando su hijo al cuidado de sus padres, obtuvo la nacionalidad en 2002, pero pasaron unos años más hasta que se dieran las condiciones que ella consideraba necesarias para poder reagrupar a su hijo que llegó a Madrid en 2007, con dieciséis años.

Entonces ya ahí resolvimos: «Vamos a traernos al hijo».

Tu hijo, ¿con quién estaba?

Con mi madre y mi padre. Cuando nos separamos estaba de meses el niño. Y mi madre, cuando yo trabajaba en la zona [franca], ella le cuidaba, y cuando vine para acá, ella le tuvo al cuidado. Entonces ya después nos fuimos de ahí, que vivíamos en Laguna, y nos conseguimos un piso en San Cristóbal, y en San Cristóbal estuvimos unos cinco meses. Y de ahí que nos lo íbamos a traer, hubo un conflicto una vez de un dominicano que mató a un español, estaba la cosa muy fuerte y cogimos miedo y no lo trajimos. Entonces ya después, pues ya decidimos, ya que estaba la cosa más tranquila, nos buscamos un piso y nos lo traemos.

$Y$ ahora, ¿desde cuándo está aquí?

Vino en noviembre. Sí, lleva poco.

$Y$ es la primera vez que vivís en familia realmente. Menudo cambio...

Sííi. Un cambio...

$[\ldots]$

¿Cómo decidisteis traer a tu hijo? ¿Lo decidisteis entre los dos? ¿Quién tomó la decisión?

El hijo estaba allí que quería venir, que quería venir. Yo por un lado no me lo quería traer por la situación en la que estaba aquí. Y ya después lo decidimos los dos. Entonces ya entre los dos lo decidimos, dijimos: «Ya estamos preparados y ya lo podemos hacer».

[...] 
¿Hay alguna diferencia entre cuando tenias residencia y ahora con la nacionalidad?

Te es más fácil, porque con la primera residencia no te puedes ir a otros países, y con la doble nacionalidad sí te puedes ir. Y la doble nacionalidad te la dan por tantos años, que te puedes ir a tu país y estarte unos cuantos años. Hay mucha diferencia.

(Altagracia, República Dominicana, reside en Madrid)

Si bien las normativas migratorias no son el único condicionante de las nuevas formas de organización familiar que protagonizan las familias migrantes latinoamericanas, sin duda, moldean las estrategias desplegadas por las personas migrantes y complejizan los procesos de reagrupación familiar.

\section{Notas finales}

Nuestro objetivo en este artículo ha sido analizar los vínculos entre la política migratoria familiar y las estrategias de reagrupación de las familias migrantes latinoamericanas. Las actuales políticas de migración familiar, además de profundizar los procesos de estratificación cívica, inciden en las formas de organización familiar y consolidan los procesos de transnacionalismo.

La tematización de la inmigración en términos de integración pasa por el tratamiento de las familias migrantes como diana de las políticas de intervención. Tras unos primeros años de la gestión de las migraciones en clave masculina y de temporalidad, en los que se mostraba una aparente inexistencia de las mujeres y las familias, hemos pasado a una reciente preocupación e hipervisualización del protagonismo que se les atribuye a ambas cuando se habla de integración. Calificadas como responsables de las tareas de reproducción de todos los miembros de la unidad familiar, son las madres esposas a quienes se culpa de los fracasos de integración debido a sus ausencias en los hogares. Reclamos que se oyen con más fuerza cuando se habla de jóvenes problemáticos y descontrolados de origen inmigrante o de familias desestructuradas y reconstituidas a partir de los procesos migratorios en los que las madres ejercen un claro papel de mantenedoras económicas del hogar, con dificultades para compaginar vida familiar y laboral. Un ejemplo más de que la inclusión de las mujeres en las políticas de migración no responde tanto a un reconocimiento de sus derechos en tanto que persona, como a su posición en la unidad doméstica y su función bisagra para con el resto de la familia.

Las políticas migratorias están atravesadas por concepciones hegemónicas y estereotipadas sobre las familias migrantes y los roles asignados a varones y mujeres. Estas representaciones condicionan las maneras como se gestiona la intervención con población inmigrante desde las administraciones públicas, cada vez menos pensadas en términos familiares, puesto que fomentan los retornos y obvian las situaciones de vulnerabilidad e invisibilidad en las que están ancladas las mujeres (especialmente las dedicadas a los cuidados y al trabajo sexual). 
El análisis de la política migratoria española desde la perspectiva de género demuestra que estas políticas siguen fuertemente diseñadas desde un enfoque androcéntrico, muy a pesar de que las mujeres sean los primeros eslabones de algunas cadenas migratorias, del claro proceso de feminización de la inmigración que caracteriza al contexto español, de la presencia cada vez mayor de las mujeres en los servicios sociales públicos (sobre todo para gestionar asuntos familiares) y del reiterado uso que las políticas han hecho de las mismas como herramientas de integración. Desde las políticas y sus prácticas, las mujeres continúan siendo pensadas y tratadas como dependientes de sus maridos, muy a pesar de que, cuando se trata de cuestiones de intervención social, se las erija como responsables y objeto de prestaciones sociales condicionadas por su buen quehacer (o no) familiar. Paradojas que operan sobre las mujeres migrantes y sus familias, a quienes, primero, se les cercena su derecho a vivir en familia (limitando beneficios de una red familiar para la satisfacción de necesidades de todo tipo) y, posteriormente, se les repudia por el modelo de familia en el que viven, por los impactos negativos de desatención y desprotección que sufren sus miembros. Situación que se agudiza en tiempos de crisis económica, recortes de prestaciones sociales y ausencia de un colchón familiar que amortigüe.

La inclusión de la perspectiva de género en las políticas públicas se limita a tratar las problemáticas de las mujeres. Desde esta mirada, se pueden resumir algunas imágenes que subyacen en documentos, discursos y prácticas que tienen por objeto a las mujeres migrantes: estabilizadoras de la unidad familiar, garantes del mantenimiento de la "cultura de origen» y mediadoras entre la «cultura de origen» y la "cultura de la sociedad receptora». Figuras extremas de alteridad, consideradas el reverso de la (imaginada) «cultura europea». En las políticas de igualdad de género, las migraciones sólo aparecen en referencia a las mujeres migrantes concebidas como grupo en riesgo de exclusión y/o de vulnerabilidad. Ni los varones ni las familias migrantes son objeto de estas intervenciones, que tampoco son tenidas en cuenta en las iniciativas para la conciliación de la vida familiar y laboral, en tanto que se obvia su condición de trabajadoras, también fuera del hogar.

Las políticas de migración familiar impulsan la estratificación cívica a lo largo de varios ejes: condicionamientos restrictivos vinculados a la concesión de permisos relacionados con la familia, conceptos conservadores de familia que fracasan en acomodar formas de vida familiar "no convencionales», atribución de roles según genero y diversidad de derechos según orígenes nacionales y para categorías diferentes de migrantes, como migrantes irregulares, migrantes con permiso de trabajo inicial, migrantes con permiso de trabajo de larga duración, migrantes con tarjeta azul, migrantes con nacionalidad española, migrantes con pasaportes comunitarios. Cada una de estas jerarquías de población tiene un acceso desigual a la vida en familia que ha dejado de ser un derecho para convertirse en una prerrogativa del estado receptor, en tanto su disfrute está condicionado por la situación jurídica, laboral y los ingresos económicos de las personas solicitantes. Privilegio atravesado, a su vez, por la discrecionalidad 
moralista del modelo de familia ideal que se desea tener y por la discrecionalidad burocrática profesionalizada que lo gestiona.

Que los criterios sean objetivos no significa que no operen de manera diferente. Generalmente, el trabajador inmigrante imaginado por los elaboradores de políticas es masculino, y esto genera que una misma normativa tenga efectos diferenciadores entre varones y mujeres. Las condiciones laborales particulares de las mujeres migrantes que trabajan en el servicio doméstico, en el sector cuidados y en el trabajo sexual (en muchas ocasiones bajo modalidades de neoservilismo, con ingresos insuficientes o no siempre reflejados en un contrato, residencia en el lugar de trabajo, salarios bajos, inestabilidad) hace muy difícil cumplir con los requisitos de ingresos y de vivienda establecidos por la legislación de reagrupación familiar. Cuando las mujeres se transforman en las reagrupantes de varones e hijos, se encuentran con mayores dificultades para cumplir con las exigencias jurídicas y económicas de la normativa, debido a su precaria inserción laboral y a la permanencia de muchas de ellas en el servicio doméstico interno.

Las normativas migratorias restrictivas han obstaculizado los proyectos migratorios familiares y, en este marco, la población migrante latinoamericana y sus familias han desplegado distintas estrategias para sortear las trabas a su movilidad. En unos casos, las estrategias más reiteradas en nuestras entrevistas son la reagrupación por vías informales en el caso de quienes no necesitaban visado y la prolongación de los distanciamientos familiares, junto con la organización y la supervisión a distancia del cuidado familiar en origen, en algunos casos hasta lograr cumplir con los requisitos de la reunificación formal, para, posteriormente, poner en marcha una reagrupación selectiva y escalonada de hijos, hijas, cónyuges y/o ascendientes. En otros casos, ante las dificultades para organizar el cuidado familiar en destino, se decantaron por una consolidación de maternidades y/o paternidades transnacionales. Pero estas estrategias nunca son definitivas, se van redefiniendo en relación con las transformaciones jurídicas, sociales y económicas de las sociedades de destino y de origen, y también en función de los cambios en los estatutos jurídicos de las migrantes y los migrantes. La nacionalización, por ejemplo, implica una ampliación del derecho a la movilidad y a la vida en familia y abre el camino a nuevos arreglos familiares, donde son habituales las estancias temporales alternadas en el lugar de emigración y de inmigración de distintos miembros de la familia, principalmente mayores, jóvenes y niños.

El contexto actual plantea nuevos interrogantes sobre las formas de organización familiar de la población migrante latinoamericana que es necesario explorar con detenimiento. En el marco global de una crisis económica generalizada, la pérdida de bienestar en las familias migrantes, junto con el endurecimiento de las políticas y el control migratorio, añadido a la creciente problematización de la presencia inmigrante en las sociedades de inmigración, se están generando transformaciones en los proyectos migratorios de familias latinoamericanas que, en ciertos casos, incluyen el retorno a los lugares de origen. Los resultados preliminares de nuestro trabajo de campo 
en curso señalan que si, hace una década, se elegía al miembro del grupo doméstico que reunía las mejores condiciones para migrar, actualmente se reflexiona sobre cuál es la mejor maniobra para combinar el retorno de algunos integrantes y la permanencia de otros que puedan seguir generando recursos económicos en destino.

\section{Referencias bibliográficas}

Agrela Romero, Belén (2006). Análisis antropológico de las politicas sociales dirigidas a la población inmigrante. Tesis doctoral. Universidad de Granada. Departamento de Trabajo Social y Servicios Sociales (inédito).

- (2009). «De los significados género e inmigración (re)producidos en las políticas sociales y sus consecuencias para la acción e integración social». En: CACHÓN, Lorenzo y LAPARRA, Miguel (comps.). Inmigración y politicas sociales. Barcelona: Bellaterra.

- (2012). "Towards a model of externalisation and denationalisation of care? The role of female migrant care workers for dependent older people in Spain». European Journal of Social Work, 15:1, 45-61.

Agrela Romero, Belén; Gil Araujo, Sandra (2005). «Constructing Otherness: The Management of Migration and Diversity in the Spanish Context». European Journal of International Migration and Ethnic Relations, 43/44/45, 9-34.

Agrela Romero, Belén; Martín Palomo, Ma Teresa; Langa Rosado, Delia (Coords.) (2010). «Estado de Bienestar y cuidados: entre el modelo familista, la institucionalización y la desnacionalización del cuidado». Monográfico de la revista Alternativas. Cuadernos de Trabajo Social, 17.

ApARICIO, Rosa (2007). «Las "segundas generaciones" en España: marroquíes, dominicanos, peruanos». Cuadernos Europeos de Deusto, 36, 19-56.

Aparicio, Rosa y GimÉnEZ, Carlos (2003). Migración colombiana en España. Ginebra: OIM-Naciones Unidas.

BaUbÖCK, Rainer (2004). «Civic Citizenship: A New Concept for a New Europe». En: SÜsSMUTH, Rita y WeIDENFELD, Werner (eds.). Managing Integration: The European Union's Responsibilities Towards Immigrants. Gütersloh: Brookings Inst Pr.

BhABHA, Jacqueline y SHUTTER, Sue (eds.) (1994). Women's Movement: Women under Immigration, Nationality and Refugee Law. Londres: Trentham Books.

B.O.E. (2000). Proyecto de Ley Orgánica de reforma de la Ley Orgánica 4/2000, de 11 de enero, sobre derechos y libertades de los extranjeros en España y su integración social.

CAmarero, Luis y García-Borrego, Ignacio (2004). «Los paisajes familiares de la inmigración». Revista Española de Sociología, 4, 173-198.

CARLING, Jorgen (2005). Gender Dimensions of International Migration [en línea]. Ginebra: GCIM. <http://www.prio.no/sptrans/-259065811/file46701_gmp_ no_35.pdf>.

CARRASQUilla Coral, María Claudia; EcheverRi Buriticá, María Margarita (2003). «Los procesos de integración social de los jóvenes ecuatorianos y colombianos en España: un juego identitario en los proyectos migratorios». Revista de la Juventud del INJUVE, 60, 89-100.

CIIMU (2004). Informe 2004: La infancia i les famílies als inicis del segle XXI. Barcelona: CIIMU. 
Colectivo IOE y FernándeZ, Mercedes (2010). Encuesta Nacional de Inmigrantes 2007: Mercado de trabajo y las redes sociales de los migrantes. Madrid: Ministerio de Trabajo e Inmigración.

Dirección General de Migraciones (2005). Plan para la integración social de los inmigrantes. Madrid: Ministerio de Asuntos Sociales.

ECHEVERRI BURITICÁ, María Margarita (2005). «Fracturas identitarias: circunstancias migratorias y procesos de integración social de los jóvenes colombianos en España». Migraciones Internacionales [en línea], 3 (1), 141-164. <http://www2.colef.mx/ migracionesinternacionales/revistas/MI08/n08-141-164.pdf>.

- (2010). «Son diez horas de viaje y cinco que te meten encima. De lo colombiano a lo latinoamericano: identidades migratorias juveniles en España». En: GrUPO INTERDISCIPLINARIO DE INVESTIGADOR@S MigRANTES (coord.). Familias, niños, niñas y jóvenes migrantes: Rompiendo estereotipos. Madrid: IEPALA-Casa Encendida-Fundación Social Caja Madrid.

ESCRIVÁ, Ángeles (1997). "Control, composition and character of new migration to south-west Europe: the case of Peruvian women in Barcelona». New Community, 23, 1, 43-57.

- (2000). «¿Empleadas de por vida? Peruanas en el servicio doméstico de Barcelona». Papers, 60, 327-342.

European COMMISSION (2003). Communication from the Commission to the Council, the European Parliament, the European Economic and Social Council and the Committee of the Regions on immigration, integration and employment, COM (2003) 336 final. Bruselas, 3 de junio de 2003.

FrEeDMAN, Jane (ed.) (2003). Gender and Insecurity: Migrant Women in Europe. Hants: Aldershot.

Gil Araujo, Sandra (2008a). «La política migratoria de la Unión Europea durante 2007». En: SOS RACISMO. Informe anual 2008. Sobre el racismo en el Estado espanol. Barcelona: Icaria.

- (2008b). «Migraciones latinoamericanas hacia el Estado español: La reactivación del sistema migratorio transatlántico». En: RODRíGUEZ, Ileana y MARTínEZ, Josebe (coords.). Postcolonialidades históricas: (in)visibilidades hispanoamericanas/colonialismos ibéricos. Barcelona: Anthropos.

- (2009). «Civic Stratification, Gender, and Family Migration Policies: An exploratory Investigation of Migrants involved in Family Migration in Spain». NODE interview analysis [en línea]. Viena: BMWF/ICMPD. <http://research.icmpd.org/ fileadmin/Research-Website/Project_material/NODE/ES_Interview_Analysis. pdf $>$.

- (2010). «Políticas de migración familiar en Europa: El gobierno de la inmigración a través de las familias». En: GARCía, Antonio; GADEA, María Elena y PEDrEÑO, Andrés (eds.). Tránsitos migratorios: contextos transnacionales y proyectos familiares en las migraciones actuales. Murcia: Universidad de Murcia.

Gil Araujo, Sandra y Agrela Romero, Belén (2008). «Un mundo en movimiento: Contextualización de las migraciones internacionales en Europa y América Latina». Revista de Derecho Migratorio y Extranjería, 18, 263-283.

Gil Araujo, Sandra y GOnZÁlez, Tania (en prensa). «Migración, género y trabajo en España: El tránsito obligado de las trabajadoras inmigrantes por el empleo de hogar». Revista Mora.

Gregorio Gil, Carmen (1998). Migración femenina: Su impacto en las relaciones de género. Madrid: Narcea. 
Gregorio Gil, Carmen (2002). «La movilidad transnacional de las mujeres: entre la negociación y el control de sus ausencias y presencias». En: GREGORIO GIL, Carmen y Agrela Romero, Belén (eds.). Mujeres de un solo mundo: globalización y multiculturalismo. Granada: Universidad de Granada.

HERrAnZ, Yolanda (1998). «La inmigración latinoamericana en diferentes contextos de recepción». Migraciones, 3, 31-51.

Herrera, Gioconda (2004). "Género y familias transnacionales: emigración ecuatoriana a Estados Unidos y España». Actas del $4^{\circ}$ Congreso sobre la Inmigración en España: Ciudadanía y Participación. Girona: Universitat de Girona, UAB, UB, Universidad de Lleida, Universitat Rovira i Virgili, Institut Europeu de la Mediterrrània, Federació de Col-lectius d'Inmigrants de Catalunya. Publicado en CD-ROM.

Hinojosa Gordonava, Alfonso (2009). Buscando la vida: Familias bolivianas transnacionales en España [en línea]. CLACSO-Fundación PIEB: La Paz. <http://bibliotecavirtual.clacso.org.ar/ar/libros/coedicion/hinojosa/>.

INSTRAW-OIM (2007). Género y remesas: Migración colombiana del AMCO hacia España [en línea]. Ginebra: INSTRAW. <http://www.oim.org.co/VistaPublicaciones/tabid/166/smid/522/ArticleID/129/reftab/74/language/en-US/Default. aspx -OIM>.

JiménEZ Álvarez, Mercedes (2005). Las Otras Migraciones: la Emigración de Menores Marroquies no Acompañados a España. Madrid: Akal.

King, Rusell; Thomson, Mark; Fielding, Tony y Warnes, Tony (2005). "Gender, Age and Generation». Imiscoe State of the Art Report [en línea]. Cluster C8. <http:// www.imiscoe.org/workingpapers/index.html>.

KOFMAN, Eleonore (2002). «Contemporary European Migration, Civic Stratification and Citizenship». Political Geography, 21, 1035-1054.

- (2004). «Family-Related Migration: A Critical Review of European Studies». Journal of Ethnic and Migration Studies, 30, 2, 243-262.

Kofman, Eleonore y Meeoo, Veena (2008). "Chapter 6. Family Migration». En: IOM. World Migration 2008. Managing Labour Mobility in the Evolving Global Economy [en línea]. Ginebra: International Organization for Migration. <http:// www.iom.int/jahia/webdav/site/myjahiasite/shared/shared/mainsite/published_ docs/studies_and_reports/WMR2008/Ch6_WMR08.pdf>.

Kofman, Eleonore; Kohli, Martin; Kraler, Albert y Schmoll, Camille (eds.) (2011). Gender, Generations, and the Family in International Migration. Amsterdam: Amsterdam University Press-IMISCOE Research.

Koopmans, Ruud y Statham, Paul (2000). «Migration and Ethnic Relations as a Field of Political Contention: An Opportunity Structure Approach». En: KoopMAns, Ruud y STATHAM, Paul. Challenging Immigration and Ethic Relacions Politics: Comparative European Perspectives. Oxford: Oxford University Press.

Lagomarsino, Francesca (2004). Fra Guayaquil e Genova: Donne e famiglie migranti dall'Ecuador. Tesis de doctorado, XVI ciclo. Génova: Università di Genova.

LevitT, Peggy y Walter, Mary (eds.) (2002). The Changing Face of Home: The Transnational Lives of the Second Generation. Nueva York: Russell Sage Publication.

Mahler, Sara y Pessar, Patricia (2006). "Gender Matters: Ethnographers Bring Gender From the Periphery toward the Core of Migration Studies». International Migration Review, 40, 1, 27-63. 
Medina Villegas, María Claudia (2009). Los ausentes están siempre presentes. Una aproximación interpretativa de la experiencia materno-filial transnacional entre España y Colombia. Tesis doctoral (inédita). Madrid: Universidad Complutense de Madrid.

Morris, Lydia (2002). Managing Migration: Civic Stratification and Migrants' Rights. Londres: Routledge.

- (2003). "Managing Contradiction: Civic Stratification and Migrants' Rights». International Migration Review, 37, 1, 74-100.

Observatorio Permanente de InMIGRACIÓn (2010). Extranjeros con certificado de registro o tarjeta de residencia en vigor y extranjeros con autorización de estancia por estudios en vigor a 31 de marzo de 2010. Madrid: Ministerio de Trabajo e Inmigración.

Oso, Laura (2002). «Estrategias migratorias de las mujeres ecuatorianas y colombianas en situación irregular: servicio doméstico y prostitución en Galicia y Pamplona». Ponencia presentada en el II Congreso sobre Migración en España. Madrid. CDROM.

- (2007). «Migración, género y hogares transnacionales». Ponencia presentada en el $V$ Congreso sobre la inmigración en España, Valencia, 21 al 24 de marzo.

PARElla, Sònia y CAVALCANTI, Leonardo (2007). «Una aproximación cualitativa a las remesas de los inmigrantes peruanos y ecuatorianos en España y a su impacto en los hogares transnacionales». Revista Española de Investigaciones Sociológicas, 116, 241-267.

- (2010). «Dinámicas familiares transnacionales y migración femenina: una exploración del contexto migratorio boliviano en España». En: GRUPO INTERDISCIPLINARIO DE INVESTIGADOR@S MigRANTES (coord.). Familias, niños, niñas y jóvenes migrantes: Rompiendo estereotipos. Madrid: IEPALA-Casa Encendida-Fundación Social Caja Madrid.

Pedone, Claudia (2004a). "Tú siempre jalas a los tuyos»: Cadenas y redes migratorias de las familias ecuatorianas hacia España. Tesis doctoral. Barcelona: Universitat Autònoma de Barcelona. Inédita.

- (2004b). «La inmigración ecuatoriana: pros y contras de una estrategia familiar para enfrentar la crisis». En: CARRASCO, Silvia (ed.). Inmigración, contexto familiar y educación: Procesos y experiencias de la población marroqui, ecuatoriana, china y senegambiana. Barcelona: Els Llibres de l'ICE. Serie Educación y Sociedad. Servei de publicacions de la UAB.

- (2005a). «Relazioni di genere e catene familiari in un contesto migratorio internazionale». En: Ambrosini, Maurizio y QueIrolo PALMAs, Luca (eds). I Latinos alla scoperta dell'Europa: Nuove migrazioni e spazi della cittadinanza. Milán: Fratelli.

- (2005b). "“Tú siempre jalas a los tuyos”: Cadenas y redes migratorias de las familias ecuatorianas hacia España». En: Herrera, Gioconda; CARrillo, María Cristina y TOrRes, Alicia (eds.). La Migración Ecuatoriana: Transnacionalismo, redes e identidades. Quito: FLACSO-PMCD.

- (2006a). Estrategias y poder: "Tú siempre jalas a los tuyos». Quito: Abya-YalaPMCD.

- (2006b). De l'Equador a Catalunya: El paper de la família i les xarxes migratòries. Barcelona: Mediterrània.

- (2006c). «Los cambios familiares y educativos en los actuales contextos migratorios ecuatorianos: una perspectiva transatlántica». Athenea Digital: Revista de Pensamiento e Investigación Social, 10, 154-171. 
Pedone, Claudia (2007). «Familias transnacionales ecuatorianas: estrategias productivas y reproductivas». En: Bretón, Víctor; García, Francisco; Jové, Antoni y Vilalta, María José (eds.). Ciudadanía y Exclusión: Ecuador y España frente al espejo. Madrid: Los Libros de la Catarata.

- (2008). “"Varones aventureros” vs. "Madres que abandonan”: Reconstrucción de las relaciones familiares a partir de la migración ecuatoriana». Revista Interdisciplinar da Mobilidade Humana, XVI, 30, 45-64.

- (2009). «D’Equador a Catalunya: La gestió de la vida quotidiana de les famílies migrants». Barcelona Societat: Revista de Coneixement i Análisi Social, 15, 81-87.

- (2010). "Lo de migrar me lo tomaría con calma”: Representaciones sociales de jóvenes en torno al proyecto migratorio familiar». En: GARCíA, Antonio; GADEA, María Elena y PEDRENO, Andrés (eds.). Tránsitos migratorios: Contextos transnacionales y proyectos familiares en las migraciones actuales. Murcia: Universidad de Murcia.

Pedone, Claudia y Gil Araujo, Sandra (2008). «Maternidades transnacionales entre América Latina y el Estado español: El impacto de las políticas migratorias en las estrategias de reagrupación familiar». En: SolÉ, Carlota; PARElla, Sònia y CAVALCANTI, Leonardo (coords.). Nuevos retos del transnacionalismo en el estudio de las migraciones. Madrid: Observatorio Permanente para la Inmigración.

Pedone, Claudia; Gil Araujo, Sandra; Agrela Romero, Belén y Solavagione, Lucía (2010). «Urban Intercultural Spaces and Social Movements». Workshop titulado: Use of Public Spaces and Intercultural Relations". Proyecto Europeo GE.M.I.C.— "Gender, Migration and Intercultural Interactions in the Mediterranean and South East Europe: an interdisciplinary perspective”. Barcelona, CIIMU, 5-6 marzo de 2010.

Riaño, Yvonne (2007). «Migration des femmes latino-américaines universitaires en Suisse: Géographies migratoires, motifs de migration et questions de genre». En: Bolzman, Claudio; CARBajal, Myrian y MaInARdi, Giuditta (eds.). La Suisse au rythme latino: Dynamiques migratoires des Latino-Américains. Ginebra: IES Editions.

Rivas Rivas, Ana María y GonZÁlvez Torralba, Herminia (2010). Familias transnacionales colombianas: Transformaciones y permanencias en las relaciones familiares y de género. Madrid: Libros de la Catarata.

SASSEN, Saskia (2003). Contrageografias de la globalización: Género y ciudadanía en los circuitos transfronterizos. Madrid: Traficantes de Sueños.

Solé, Carlota y Parella, Sònia (2005). «Discursos sobre la "maternidad transnacional" de las mujeres de origen latinoamericano residentes en Barcelona» [en línea]. Jornadas Mobilités au féminin. Tánger, 15 al 19 de noviembre. <http:// www.mmsh.univ-aix.fr/lames/Papers/ParellaSole_ES.pdf>.

SORENSEN, Nina (2004). «Globalización, género y migración transnacional: El caso de la diáspora dominicana». En: EsCRIVÁ, Ángeles y RIBAS, Natalia (coords.). Migraciones y desarrollo: Estudios sobre remesas y otras prácticas transnacionales en España. Córdoba: CSIC.

- (2005a). «Migración, género y desarrollo: el caso dominicano». En: ZuÑIGA GARCÍA-FALSES, Nieves (coord.). La migración: Un camino entre el desarrollo y la cooperación [en línea]. Madrid: Centro de Investigación para la Paz, 163-182. <http://www.fuhem.es/media/ecosocial/file/Cohesi\%C3\%B3n\%20 Social/Inmigraci\%C3\%B3n/NYBERG\%20SORENSEN,\%20Ninna,\%20 Migraci\%C3\%B3n,\%20g\%C3\%A9nero\%20y\%20desarrollo.pdf>. 
Sorensen, Nina (2005b). "Narratives of Longing, Belonging and Caring in the Dominican Diaspora». En: Besson, Jean y OLWIG, Fog (eds.). Caribbean Narratives of Belonging: Fields of Relations, Sites of Identity. Oxford: Macmillan.

SOYSAL, Yasemin (1996). Limits of Citizenships: Migrants and Postnational Membership in Europe. Chicago: University of Chicago Press.

SuÁREZ NAVAS, Liliana y CRESPO, Paloma (2004). «Familias en movimiento: El caso de las mujeres rumanas en España». Migraciones, 21, 235-257.

Tornos, Antonio; Aparicio, Rosa; Labrador, J.; García, M. y Muñoz, H. (1997). Los Peruanos que vienen. Madrid: Universidad Pontificia Comillas. 